\title{
Comparison of Levobupivacaine and Lidocaine for Post-Operative Analgesia Following Tympanoplasty
}

\author{
Anagha Yogesh Rajguru ${ }^{1}$, Mannuru Khaleel Basha², Yarlagadda Lakshmi Sravya ${ }^{3}$, \\ Tripti Rai ${ }^{4}$, Naman Pincha ${ }^{5}$, Kaenat Ahmed ${ }^{6}$, Sanket Chandrasekhar Prabhune \\ 1, 2, 3, 4, 5, 6, 7 Department of Otorhinolaryngology, Krishna Institute of Medical Sciences, \\ Deemed to Be University, Karad, Maharashtra, India.
}

\section{ABSTRACT}

\section{BACKGROUND}

A pure s-enantiomer of bupivacaine known as levobupivacaine, is now considered a safer alternative for regional anaesthesia than a racemic solution, bupivacaine since it is as efficacious as bupivacaine, but with better pharmacokinetics. Levobupivacaine is clinically tolerated well in cases requiring regional anaesthesia with both bolus administration and post-operative infusion. There are very few incidence of Adverse Drug Reactions (ADR) if administration is monitored appropriately as most ADRs are due to mistakes causing systemic exposure of drug. Hypersensitivity reaction to drug or pharmacological effects of anaesthesia though rare can also cause ADRs. ${ }^{1}$ Lidocaine (Xylocaine), is available commonly in a $0.5 \%$ or $1 \%$ solution, though several more concentrations are available. It is the most commonly used infiltrative amide anaesthetic. Higher concentrations show no difference in pharmacodynamics but may increase the risk of toxicity. ${ }^{2}$ The duration of action may be increased by addition of epinephrine. It can be added in concentrations of 1:100,000 or 1:200,000. This is seen to increase the maximum dose of drug and also reduces blood loss. ${ }^{3}$ Recent studies have found this combination to be safe to use in nose, ears, fingers and toes.

\section{METHODS}

A randomized comparative study was carried out in a tertiary care teaching hospital, Karad. A total of 112 cases was enrolled in the study who were having chronic suppurative otitis media and who require surgical management by tympanoplasty. Cases with a previous history of ear surgery were excluded. The enrolled cases were classified into group I and group II alternatively and the group I cases were given levobupivacaine $0.5 \%$ and group II were given lidocaine $2 \%$. Infiltration with local anaesthetic was given in post auricular region. Perioperative analgesics were not given. Post-operative pain was measured by using VAS score and comparison of both groups was done by the Mann Whitney U test.

\section{RESULTS}

Levobupivacaine $(8.6 \mathrm{~mL})$ and lidocaine $(9.2 \mathrm{~mL})$ used during tympanoplasty in cases were stable throughout the procedure and no post-operative complications were noticed. The mean time of analgesic requirement was $186.43 \pm 91.04$ minutes and $329.54 \pm 135.82$ minutes respectively in levobupivacaine group and lidocaine group. The mean quantity of analgesics used was $1.95 \pm 1.01$ tablets and $3.34 \pm 1.10$ tablets in the levobupivacaine and lidocaine groups respectively.

\section{CONCLUSIONS}

Levobupivacaine when used with a local anaesthetic in cases of tympanoplasty is a more effective analgesic post operatively when compared to lidocaine, thus increasing post-operative comfort.

\section{KEY WORDS}

Tympanoplasty, Local Anaesthesia, Levobupivacaine, Lidocaine, Post-Operatively
Corresponding Author: Mannuru Khaleel Basha. Department of ENT, Krishna Institute of Medical Sciences University, Karad415110, Maharashtra, India. E-mail: khaleelsona50@gmail.com

DOI: $10.14260 / \mathrm{jemds} / 2020 / 664$

How to Cite This Article:

Rajguru AY, Basha MK, Sravya YL, et al. Comparison of levobupivacaine and lidocaine for post-operative analgesia following tympanoplasty. I Evolution Med Dent Sci 2020;9(41):3029-3032, DOI: $10.14260 / \mathrm{jemds} / 2020 / 664$

Submission 10-07-2020,

Peer Review 02-09-2020,

Acceptance 09-09-2020,

Published 12-10-2020.

Copyright @ 2020 Anagha Yogesh Rajguru et al. This is an open access article distributed under Creative Commons Attribution License [Attribution 4.0 International (CC BY 4.0)] 


\section{BACKGROUND}

Local and General Anaesthesia (LA and GA) are two different ways of anaesthesia used in ear surgery. The choice of anaesthesia depends mainly on the surgeon's preference in ear surgery, even though LA and GA have their own advantages and disadvantages. GA offers comfort to the patient and ease to the surgeon, especially in cases who cannot tolerate the procedures under LA. However, LA decreases the operative time, improves haemostasis, and allows intraoperative hearing assessment. A wide range of otologic surgeries, including myringoplasty, tympanoplasty, mastoidectomy, ossiculoplasty, and stapes surgery can be performed under LA. ${ }^{4}$ Local anaesthetics are used to ease the pain in all operative cases before and after the operation, pain is the most common complaint. Tympanoplasty is a common procedure done with local anaesthesia by otorhinolaryngologists.

There are only a few studies on post-operative tympanoplasty pain reduction. Pain, post-surgery is due to expression of pain mediators due to surgical trauma. 5 The first 24 hours after surgery are when the maximum level of pain is experienced, therefore maximum level of analgesics are needed. Post op anxiety is significantly reduced by appropriate pain management. ${ }^{6}$ Lignocaine is a commonly used local anaesthetic. It can also be used to treat ventricular tachycardia and to perform nerve blocks. Also known as lidocaine, it can be combined with epinephrine (adrenaline) to allow an increase in the maximum dose, attain haemostasis and increase the duration of action. The onset of action is within four minutes and the duration of action is about thirty minutes to three hours. Local application of lidocaine to skin and mucous membrane may be used. ${ }^{7}$

Lidocaine is the commonly used local anaesthetic agent and because of its fast -acting action and short half-life, cannot control the post-operative pain for a long duration. Bupivacaine and Lidocaine have similar pharmacological qualities. Levobupivacaine is the S-enantiomer of bupivacaine. The mechanism of action of Levobupivacaine is via the reversal of blockade of neuronal sodium channels. The progression of anaesthesia is generally dependent on the myelination and diameter of nerve fibre, as it in turn affects the conduction velocity of the nerve. Small myelinated nerves are blocked more easily than large unmyelinated nerves. The drug binds to the intracellular part of the sodium channels specifically, thus preventing depolarization by blocking the sodium influx into the nerve cell. It blocks the sensory and motor nerve conduction by mainly blocking the voltage gated sodium channels on the nerve cell. It also similarly interferes with impulse transmission and conduction in other tissues. ${ }^{8}$ Levobupivacaine, although as efficacious as bupivacaine as a local anaesthetic agent, is less cardio toxic and neurotoxic than the later. ${ }^{9}$

A comparison of cases that underwent tympanoplasty with long acting levobupivacaine and those with short acting lidocaine as an infiltrative anaesthetic, with respect to postoperative pain and requirement of post-operative anaesthesia was done.

\section{METHODS}

It is a prospective single blind randomized comparative study done at ENT department of a tertiary care teaching hospital, Karad. A total of 112 participants who were suffering from chronic suppurative otitis media requiring tympanoplasty were included in the study and randomized into two groups where the group I received levobupivacaine and group II received lidocaine.

The present study was conducted in a tertiary care teaching hospital, Karad from July 2019 to March 2020. Due to the short duration of our study, it was planned with at least 85 cases. However, keeping the possibilities of drop out during follow up, it was decided to enrol a minimum of 112 cases, and hence the sample size was 112 . The present study included 112 cases with chronic suppurative otitis media that were scheduled for tympanoplasty under local anaesthetic. All cases having a history of traumatic tympanic membrane perforation, congenital craniofacial anomalies, otomycosis, diabetes mellitus, compromised immunity, and atticoantral variety of CSOM were excluded from the study.

The mean age of the cases was $39.7 \pm 7.5$ years (range: 19 - 53 years). The Ethical Committee's permission was obtained. In all cases blood pressure, pulse, respiratory rate, oxygen saturation, temperature were monitored throughout the operation. The cases that had additional nasal pathologies, ECG changes, neurological diseases, hypertension, diabetes mellitus, asthma and history of allergies to local anaesthetics, and receiving or received surgical treatment for any underlying medical conditions were excluded from our study. Only tympanoplasty was performed. A simple randomization method was used to select the cases and was classified into groups I and II. Group I (56) cases received levobupivacaine $0.5 \%$ and Group II (56) received lidocaine $2 \%$. The local anaesthetic was infiltrated into the post auricular region. Preoperative medication like dexmedetomidine $10 \mathrm{mg} / \mathrm{kg}$ was used. To systematize the anaesthetics used, it was assured that both levobupivacaine and lidocaine were having 0.0125 $\mathrm{mg} / \mathrm{mL}$ adrenaline. LA injection technique involves anaesthetizing 12 points. First, 3 - $5 \mathrm{~mL}$ is injected in the post auricular region. The needle is then advanced anteriorly through the same entry under the concha and $0.5 \mathrm{~mL}$ of anaesthetic solution is injected in the posterior, the superior and inferior meatal walls. Another $0.5 \mathrm{~mL}$ is injected in the front of the helix crus to block auriculotemporal nerve, and then at the site of endaural incision at the incisura. The medial surface of the tragus is then injected to abolish sensation induced by the retractor positioned at this area, and it facilitates harvesting tragal cartilage grafts. The external meatus is opened using the Killian speculum, and $0.5-1 \mathrm{~mL}$ is injected superiorly in the bone meatus at the 12 o'clock position, posteriorly, inferiorly at the 6 o'clock position and anteriorly. Injecting the posterior and inferior ear canal skin anaesthetizes the auricular branch of the vagus nerve. The bevel of the needle is directed toward the bone, and the anaesthetic solution is injected subperiosteally. If the bevel is directed toward the lumen of the external canal, blebs will form, and the skin may be damaged. 
The injection of bone meatus by introducing the needle in the thick skin of cartilaginous meatus, and then proceeding subcutaneously until it reaches the bone meatus to infiltrate it, this simple method helps to keep the integrity of the thin skin of the bone canal. The surgery started after infiltrating the post auricular region with anaesthetic of choice (levobupivacaine $0.5 \%$ in group I and lidocaine $2 \%$ in group II). Abgel was used in all cases. Preoperatively and intraoperatively no other analgesia was used.

\section{Pain Measurement}

Visual analog scale (VAS) of 0 - 10 was used to determine the intensity of the pain, where, 0 indicates 'no pain', and 10 indicate 'severe pain'. The cases marked their pain at different times on the scale, and the results were calculated and recorded in millimetres. The measurements were repeated at the $1 \mathrm{st}, 2^{\text {nd }}, 4^{\text {th }}, 6^{\text {th }}, 8^{\text {th }}, 12^{\text {th }}$, and $24^{\text {th }}$ hours. Cases were given $500 \mathrm{mg}$ paracetamol when the pain was most severe. Timing and amount of analgesics used were recorded every time analgesia was given.

\section{Statistical Analysis}

While comprising VAS scores in the same group we use oneway ANOVA test as data was not following a normal distribution. Paired t-test was done to compare between the means of group I and group II. All data analysis had been done by using SPSS (version 20.0) for windows.

\section{RESULTS}

A mean volume of $8.6 \mathrm{~mL}$ levobupivacaine and $9.2 \mathrm{~mL}$ lidocaine was used in the cases of our study. Cases were stable throughout the procedure and no post-operative complications were noticed. The mean time required for analgesic medication was $186.43 \pm 91.04$ minutes in the levobupivacaine group and $329.54 \pm 135.82$ minutes in the lidocaine group during the post-operative period (Table 1). The difference was statistically significant between the mean times of analgesic needs of the two groups $(p<0.001)$. Oneway ANOVA test was used to compare the post-operative pain at $1^{\text {st }}, 2^{\text {nd }}, 4^{\text {th }}, 6^{\text {th }}, 8^{\text {th }}$ and $12^{\text {th }}$ hour in both levobupivacaine group and lidocaine group, the p-value of which was significant $(p<0.001)$ in both the groups. The Mean and standard deviation was calculated and compared using oneway ANOVA test at various time periods during the study. Intragroup comparisons of the groups for VAS scores of different hours indicated statistically significantly increased pain in the levobupivacaine group starting from the 2nd hour and in the lidocaine group, starting from the 6th hour compared to the $1^{\text {st }}$ hour scores of both groups $(\mathrm{p}<0.001)$ (Table 2). Unpaired t-test was done to compare between the means of both the groups (Table 3). Comparison of the amounts of analgesics used by the cases showed that in the levobupivacaine group, the mean amount of analgesics used was $1.95 \pm 1.01$ tablet, while in the lidocaine group, it was 3.34 \pm 1.10 tablets, which was statistically significant $(\mathrm{p}<0.001)$ (Table 1).

\begin{tabular}{|cccc|}
\hline Groups & $\begin{array}{c}\text { Volume of } \\
\text { Anaesthetic Used } \\
\text { Intraoperatively } \\
\text { (millilitres) }\end{array}$ & $\begin{array}{c}\text { Mean Time of } \\
\text { Analgesic } \\
\text { Requirement } \\
\text { Postoperatively } \\
\text { (minutes) }\end{array}$ & $\begin{array}{c}\text { Dosage of } \\
\text { Analgesic } \\
\text { Required } \\
\text { Postoperatively } \\
\text { (tablets) }\end{array}$ \\
$\begin{array}{c}\text { Group I } \\
\text { (Levobupivacaine) } \\
\text { Group II } \\
\text { (Lidocaine) }\end{array}$ & 8.6 & $186.43 \pm 91.04$ & $1.95 \pm 1.01$ \\
\hline Table 1. Comparison of Drug Volume Used Intraoperatively, Analgesic \\
Dosage and Time Requirement Postoperatively in Both Groups
\end{tabular}

Dosage and Time Requirement Postoperatively in Both Groups

\begin{tabular}{|c|c|c|c|c|c|c|c|c|}
\hline \multirow{4}{*}{ Groups } & \multicolumn{6}{|c|}{ Mean \pm Standard Deviation at Various } & \multirow{4}{*}{\multicolumn{2}{|c|}{$\underset{\text { Value }}{\text { F- }} \underset{\text { Value }}{\text { P- }}$}} \\
\hline & \multirow{3}{*}{$\begin{array}{c}1^{\text {st }} \\
\text { Hour }\end{array}$} & \multirow{3}{*}{$\begin{array}{l}2^{\text {nd }} \\
\text { Hour }\end{array}$} & \multicolumn{2}{|c|}{ Time Periods } & \multirow{3}{*}{$\begin{array}{c}8^{\text {th }} \\
\text { Hour }\end{array}$} & \multirow{3}{*}{$\begin{array}{l}12^{\text {th }} \\
\text { Hour }\end{array}$} & & \\
\hline & & & $4^{\text {th }}$ & $6^{\text {th }}$ & & & & \\
\hline & & & Hour & Hour & & & & \\
\hline Group I & $2.58 \pm$ & $5.33 \pm$ & $6.08 \pm$ & $7.07 \pm$ & $6.19 \pm$ & $8.37 \pm$ & & $<$ \\
\hline (Levobupivacaine) & 1.12 & 1.03 & 0.83 & 0.82 & 1.05 & 1.10 & 212.35 & $0.0001^{*}$ \\
\hline Group II & $2.30 \pm$ & $3.42 \pm$ & $3.07 \pm$ & $5.44 \pm$ & $6.53 \pm$ & $8.5 \pm$ & 372.7 & $<$ \\
\hline & 1.09 & 1.0 & 1.43 & 0.50 & 0.5 & 0.50 & & \\
\hline
\end{tabular}

\begin{tabular}{|cccccc|}
\hline Groups & Mean & SD & $\mathbf{9 5} \%$ CI & & \\
$\begin{array}{c}\text { Group I } \\
\text { (Levobupivacaine) }\end{array}$ & 5.95 & 0.99 & $5.68-6.22$ & 5.06 & $<0.0001^{*}$ \\
$\begin{array}{c}\text { Group II } \\
\text { (lidocaine) }\end{array}$ & 5.07 & 0.84 & $4.84-5.3$ & & \\
\hline Table 3. Paired t-Test to Compare Means of Group I and Group II & P-Value \\
\hline
\end{tabular}

\section{DISCUSSION}

Several advantages such as less bleeding, faster mobilization of the patient, post-operative analgesia, and the ability to test hearing intra-operatively and cost-effectiveness were observed with the use of local anaesthetics. Testing the facial nerve action, by asking the patient to smile, blow the cheeks or close the eye lids, was a good alternative for facial nerve monitoring in our study. Especially with mastoidectomy or surgeries requiring manipulations near the facial nerve such as facial nerve decompression, it is a huge advantage because of local anaesthesia. However, complications due to excessive injection at the mastoid tip or on the lateral surface of the tragus, such as temporary facial nerve paralysis may occur, which may be explained by trickling of anaesthetic solution along the tragus to the tragal pointer. In one case, temporary paralysis occurred due to direct application of local anaesthesia on a dehiscent facial nerve. Facial nerve paralysis usually recovers within a few hours, but deprives the surgeon from intraoperative testing of facial nerve action. Eustachian tube patency could be tested during operations under Local anaesthesia by asking the patient to perform Valsalva manoeuvre, or by injecting saline in the eustachian tube through a small malleable catheter and asking if the patient feels it in his or her throat. Eustachian tube patency is the key of success for all tympanoplasty operations. ${ }^{10}$ Tympanoplasty is done as a routine procedure by otorhinolaryngologyists under local anaesthesia in cooperating adults. An important hurdle to be crossed when it comes to usage of local anaesthetics in surgeries is post-operative pain management. The lower the post-operative pain, the more is the impact on healing which increases cases response and comfort ${ }^{11}$ The frequently used medications to reduce post-operative pain and inflammation are analgesics and NSAIDs. However, use of these agents frequently leads to gastrointestinal irritation, tendency to bleed and allergic reaction and other complications, which may limit their use. Cases require 
additional analgesics in post-operative period as pain will be more in the first 24 hours following surgery. To reduce this pain by using local anaesthetics is the mainstay of our study. We have compared levobupivacaine and lidocaine in our study as these have the same onset of action and their chemical properties are also similar.

The effect of lidocaine however, lasts 2 - 3 times shorter than that of levobupivacaine. ${ }^{12}$ The comparison of these two drugs in the post-operative period is conducted by comparing the VAS scores of both once every $1^{\text {st }}, 2^{\text {nd }}, 4$ th $, 6^{\text {th }}, 8^{\text {th }}, 12^{\text {th }}$ and $24^{\text {th }}$ hourly. On comparison we found out that the VAS scores of levobupivacaine were lower than lidocaine after $6^{\text {th }}$ hour and this was found to be consistent throughout the study time .This indicates the efficacy of levobupivacaine to reduce the pain. A similar study was conducted by Friedman et al ${ }^{6}$ to compare levobupivacaine and lidocaine for post-operative endoscopic sinus surgery pain. However he did not find any significant difference between the groups like in our study. In a similar study conducted by Apostol Poulos et al, ${ }^{13}$ ropivacaine and lidocaine were compared in reducing postoperative pain following tonsillectomy, where cases that received ropivacaine required lower dose of post-operative analgesics. So far, only a few studies have been conducted to compare the use of levobupivacaine and lidocaine in reducing post-operative pain following tympanoplasty. Therefore it was a felt need to conduct this study to improve the patient's response following surgery.

\section{CONCLUSIONS}

In our study, for procuring analgesic effect in post-operative tympanoplasty cases, levobupivacaine is found to be more effective when compared to lidocaine.

Financial or Other Competing Interests: None.

\section{REFERENCES}

[1] Bajwa SJS, Kaur J. Clinical profile of levobupivacaine in regional anaesthesia: a systematic review. J Anaesthesiol Clin Pharmacol 2013;29(4):530-9.
[2] Liu W, Yang X, Li C, et al. Adverse drug reactions to local anaesthetics: a systematic review. Oral Surg Oral Med Oral Pathol Oral Radiol 2013;115(3):319-27.

[3] Bernards CM, Kopacz DJ. Effect of epinephrine on lidocaine clearance in vivo: a microdialysis study in humans. Anaesthesiology 1999;91(4):962-8.

[4] Caner G, Olgun L, Gültekin G, et al. Local anaesthesia for middle ear surgery. Otolaryngol Head Neck Surg 2005;133(2):295-7.

[5] Seymour RA, Walton JG. Pain control after third molar surgery. Int J Oral Surg 1984;13(6):457-65.

[6] Friedman M, Venkatesan TK, Lang D, et al. Bupivacaine for postoperative analgesia following endoscopic sinus surgery. Laryngoscope 1996;106(11):1382-5.

[7] The American Society of Health-System Pharmacists. Archived from the original on 2015-09-06. Retrieved Aug 26, 2015.

[8] Burlacu CL, Buggy DJ. Update on local anaesthetics: focus on levobupivacaine. Ther Clin Risk Manag 2008;4(2):38192.

[9] De Cosmo G, Mascia A, Clemente A, et al. Use of levobupivacaine for the treatment of postoperative pain after thoracotomies. Minerva Anestesiol 2005;71(6):34751.

[10] El-Begermy MA, El-Begermy MM, Rabie AN, et al. Use of local anaesthesia in ear surgery: technique, modifications, advantages, and limitations over 30 years' experience. Egypt J Otolaryngol 2016;32(3):161-9.

[11] Jebeles JA, Reilly JS, Gutierrez JF, et al. Tonsillectomy and adenoidectomy pain reduction by local bupivacaine infiltration in children. Int J Pediatr Otorhinolaryngol 1993;25(1-3):149-54.

[12] Schoem SR, Watkins GL, Kuhn JJ, et al. Control of early postoperative pain with bupivacaine in pediatric tonsillectomy. Ear Nose Throat J 1993;72(8):560-3.

[13] Apostolopoulos K, Labropoulou E, Samaan R, et al. Ropivacaine compared to lidocaine for tonsillectomy under local anaesthesia. Eur Arch Otorhinolaryngol 2003;260(7):355-7. 